University of Nebraska - Lincoln

DigitalCommons@University of Nebraska - Lincoln

4-2009

\title{
A comparison between above-water surface and subsurface spectral reflectances collected over inland waters
}

\author{
Asif M. Bhatti \\ Kochi University of Technology, Japan, asifmumtaz.bhatti@kochi-tech.ac.jp \\ Donald Rundquist \\ University of Nebraska - Lincoln, drundquist1@unl.edu \\ John Schalles \\ Creighton University, jfsaqua@creighton.edu \\ Luis Ramirez \\ University of Nebraska-Lincoln, luisermz@yahoo.com \\ Seigo Nasu \\ Kochi University of Technology, Japan
}

Follow this and additional works at: https://digitalcommons.unl.edu/natrespapers

Part of the Natural Resources and Conservation Commons

Bhatti, Asif M.; Rundquist, Donald; Schalles, John; Ramirez, Luis; and Nasu, Seigo, "A comparison between above-water surface and subsurface spectral reflectances collected over inland waters" (2009). Papers in Natural Resources. 307.

https://digitalcommons.unl.edu/natrespapers/307

This Article is brought to you for free and open access by the Natural Resources, School of at DigitalCommons@University of Nebraska - Lincoln. It has been accepted for inclusion in Papers in Natural Resources by an authorized administrator of DigitalCommons@University of Nebraska - Lincoln. 


\title{
A comparison between above-water surface and subsurface spectral reflectances collected over inland waters
}

\author{
Asif M. Bhatti, ${ }^{1}$ Donald Rundquist, ${ }^{2}$ John Schalles, ${ }^{3}$ \\ Luis Ramirez, ${ }^{2}$ and Seigo Nasu ${ }^{1}$ \\ 1. Department of Infrastructure Systems Engineering, \\ Kochi University of Technology, Kami-City, Kochi, Japan \\ 2. Center for Advanced Land Management Information Technologies (CALMIT), \\ School of Natural Resources, University of Nebraska-Lincoln, Lincoln, Nebraska USA \\ 3. Biology Department, Creighton University, Omaha, Nebraska USA
}

\begin{abstract}
The objective of the research was to undertake a quantitative comparison of spectral-reflectance measurements made slightly above the surface of water bodies with the measurements made slightly below the surface. The study is focused on three rivers; two in Georgia, USA and one in Japan. As expected, the differences in reflectance are not constant and vary with the wavelength. The contribution of surface-reflection effects to the surface reflectance measured slightly above the water is both pronounced and highly variable, but although they do alter the magnitude of the upwelling signal, they do not change the general shape of the spectral profiles. The correction of surface-reflection effects by assuming a proportionality factor $(\rho)$ is not considered to be efficient for inland fresh water bodies. For in situ spectroscopy, the recommended approach is to measure upwelling radiance slightly below the water's surface as a means of minimizing extraneous noise. Researchers should be aware of the potential for diminishing the validity of findings because of measurement errors.
\end{abstract}

Keywords: above-water reflectance, subsurface reflectance, sun glint

\section{Introduction}

Field spectroscopy has an important role in environmental science in that it allows the characterization of targets and materials in situ. With proper equipment and methods, spectroradiometry can be conducted under a variety of conditions including outdoors either in full sun or with partly cloudy skies, as well as indoors using lamps for illumination. The technology allows data collection when convenient to the investigator, and one can control or eliminate variables, which often are troublesome when using aircraft or satellite data (Rundquist 2001). However, the accuracy of results depends upon a clear definition of the target under investigation, on the conditions under which measurements are 
made, and on an unbroken traceability chain with known uncertainty at each step (Milton et al. 2006). As suggested by Milton (1987), the need to understand the spectral nature, influential parameters and correct data-collection techniques are crucial for characterizing both terrestrial and aquatic targets. Poor data-collection techniques and assumptions may lead to errors in the research results, and a paper by Rundquist et al. (2004) documented the differing results obtained when spectral data are collected over cropland vegetation by means of machine-positioning versus hand-positioning of the sensor. In short, it is necessary to identify and understand the potential pitfalls in collecting data by means of a radiometer or spectroradiometer as deployed in field settings.

Field spectroscopy has been used for data collection in natural waters, and spectral reflectance is widely used for both qualitative and quantitative assessments of the constituents of the water column (Mobley 1989). Han and Rundquist (1998) documented, by means of a spectroradiometer positioned $2.5 \mathrm{~m}$ above the water, the impact of a windroughened water surface on remote measurements of turbidity. In studying the uncertainty arising from sensors being deployed in situ for the purpose of collecting optical data in a case-1 environment, Hooker and Maritorena (2000) took into account: (a) calibration; (b) the stability of an in situ sensor; (c) data-collection method and (d) data processing. Hooker (2002) evaluated above- and in-water methods for the determination of water-leaving radiance. Their fundamental finding was that it is difficult to remove the effect the surface waves, wind and other natural influences on the water's surface when collecting spectral information with a sensor positioned above the water. Doxaran et al. (2004) focused on estimating the effect of surface reflection on field measurements of upwelling radiance in turbid waters and concluded that the contribution of the surface is highly variable and always a contributor to the composite spectral signal received at the sensor.

Despite years of research and publications such as those cited above, the techniques and approaches for collecting spectral data at close-range in the field are often inconsistent and unsystematic. Researchers conducting proximal sensing of the water column tend to either make their measurements slightly above the water column or slightly below the water column, yet very few studies exist that compare the two approaches. Therefore, the present research article is intended to document and quantify the differences between the above-and in-water spectral reflectances collected on three different rivers.

\section{Theory}

The optical properties considered here are: (1) above-water surface total upwelling radiance $L_{t}(\lambda)$; (2) above-water surface spectral water-leaving radiance $L_{w}(\lambda)$; (3) the upwelling radiance just below the water surface (subsurface) $L_{u}(\lambda)$; $(4)$ the down-welling irradiance incident on the water surface $E_{\text {inc }}(\lambda)$ and (5) the reflectance quantity, sometimes referred to as water-leaving reflectance $R(\lambda)$.

The above-surface upwelling radiance $L_{\mathrm{w}}(\lambda)$ cannot be directly measured with commonly available instruments. The measured above-surface upwelling radiance in the sensor-viewing direction is the sum of the water-leaving radiance $L_{w}(\lambda)$, plus any incident sky radiance reflected by the water surface. The total radiance entering the sensor can be expressed as (Mobley 1999):

$$
L_{t}(\lambda)=L_{w}(\lambda)+L_{r}(\lambda)
$$


$L_{\mathrm{r}}$ is the surface-reflected part of the incident sky radiance $L_{\mathrm{s}}$. $L_{\mathrm{r}}$ is related to the sky radiance $L_{\mathrm{s}}$ incident on the water surface through the following equation (Mobley 1999):

$$
L_{\mathrm{r}}=\rho L_{\mathrm{s}}
$$

where $\rho$ is a proportionality factor that depends not only on direction, wavelength and wind speed but also on the sensor field-of-view and on the sky radiance distribution. The above- and below-water upwelling radiances are related by (Morel and Gentili 1996):

$$
\frac{L_{\mathrm{w}}}{L_{\mathrm{u}}}=\frac{1-r_{\mathrm{F}}}{n_{\mathrm{w}}^{2}}
$$

where $r_{\mathrm{F}}$ is the Fresnel reflectance of the surface as seen from the water side and $n_{\mathrm{w}}$ is the refractive index of water. For $r_{\mathrm{F}} 0.02$ to 0.04 and $n_{\mathrm{w}} \approx 1.34$, the following approximation was proposed (Mobley 1999 and Doxaran et al. 2004):

$$
\frac{L_{\mathrm{w}}}{L_{\mathrm{u}}} \approx 0.544
$$

\section{Methods: Data Collection}

Our research is based on field measurements of spectral reflectance made on/in three different rivers. The Altamaha River, located in Georgia, USA (31.307 N-31.335 N, 81.244 W-81.475 W), has its origin in the foothills of the Appalachians, and the river contains high clay and silt concentrations obtained from the piedmont and upper coastal plain. It drains one of the largest basins on the east coast, and is about $220 \mathrm{~km}$ in length. In situ data were collected on 11 March 2007. The second river studied was the St Mary's (30.710 N-30.761 N, 81.398 W-81.779 W), which comprises the border between Georgia and Florida, USA. It is characterized by a high colored dissolved organic matter (CDOM) concentration having an origin in the southeastern portion of the Okefenokee Swamp with tributaries from pine forest and plantations in northeastern Florida and southeastern Georgia. The St Mary's River is $144 \mathrm{~km}$ long; in situ data collection occurred on March 12, 2007. The mouths of both the Altamaha and St Mary's are on the Atlantic Ocean (EPD 2003). The final river examined was the Monobe River in Kochi, Japan on August 26, 2007. The Monobe River, Kochi, Japan has its source at Mt. Akagioyama in Tsurugi mountain range. The river is $68.12 \mathrm{~km}$ long with a basin area of $508.2 \mathrm{~km}^{2}$. The concentration of clay, silt and organic matter is generally low in the river; however, during heavy rains the turbidity increases due to soil erosion in the upstream catchment.

The field spectral data in the USA were collected by a field crew from the Center of Advanced Land Management Information Technologies (CALMIT), University of Nebraska-Lincoln, whereas the data for the Monobe River were acquired by a field crew associated with the Kochi University of Technology. The data for the three rivers were collected under clear sky conditions, with low wind speeds $(3 \sim 5 \mathrm{~m} / \mathrm{s})$. It should also be noted that the sampling stations along the rivers represented very different water-quality conditions, but the analyses described below are based upon comparison of above- and below-water measurements for the same sampling station in all cases. For example, the measurements along the St Mary's began in the ocean and were done at intervals along 
a transect up-river for a distance of several kilometers. The conditions, especially colored dissolved organic material, changed markedly as the field team progressed up-river. But again, the water-quality parameters are the same for each measurement pair (i.e. above and below the surface).

Measurements of spectral reflectance were made in the USA from a boat using a dualfiber system that included two inter-calibrated Ocean Optics USB2000 Spectroradiometers (2048 channels, 370-1000 nm). Data were collected in the spectral range of 400-900 nm with a sampling interval of $0.3 \mathrm{~nm}$ and a spectral resolution of $1.5 \mathrm{~nm}$. Radiometer \#1, equipped with a $25^{\circ}$ field-off view optical fiber, was pointed downward in the nadir direction to measure the total above-surface upwelling radiance from the water $L_{t}(\lambda)$. Radiometer \#2, equipped with an optical fiber and a cosine collector (yielding a hemispherical field of view) was pointed upward to simultaneously measure the above-surface incident irradiance $E_{\text {inc }}(\lambda)$. To measure the subsurface upwelling radiance $L_{\mathrm{u}}(\lambda)$, the optical fiber was mounted on a 2-m fixed black pole, and the tip of the optical fiber was positioned just below $(\sim 3 \mathrm{~cm})$ and just above $(1 \mathrm{~m})$ the water's surface. To match their transfer functions, the inter-calibration of the radiometers was accomplished by measuring the upwelling radiance $\left(L_{\text {cal }}\right)$ of a white Spectralon (Labshere, North Sutton, NH) reflectance standard, simultaneously with incident irradiance $\left(E_{\mathrm{cal}}\right)$. An average of 10 consecutive scans was used to collect the reflectance spectra at each of the sampling stations. The spectral-reflectance data were collected close to solar noon and changes in solar zenith angle were minimal during the period of scanning. All spectral measurements were taken over optically deep water. The data collection procedure was kept constant in all the cases. Data collection and management were performed using the CALMIT Data Acquisition Program, written by Mr. B. Leavitt, CALMIT, University of Nebraska-Lincoln. Percent spectral reflectance $R(\lambda)$ was computed as:

$$
\% R(\lambda)=\left[L(\lambda)_{\mathrm{t}} / E(\lambda)_{\mathrm{inc}}\right] \times\left[E(\lambda)_{\mathrm{cal}} / L(\lambda)_{\mathrm{cal}}\right] \times R(\lambda)_{\mathrm{cal}} \times 100
$$

$R(\lambda)_{\text {cal }}$ is the reflectance of the Spectralon panel linearly interpolated to match the band centers of each radiometer.

The dual-fiber approach results in fast measurement and it minimizes error caused by variations in irradiation conditions. One critical issue with regard to the dual-fiber approach is that the transfer functions of both radiometers must be identical. The Ocean optics instruments were tested under laboratory conditions; over a 4-h period the standard deviations (SD) of the ratio of the two transfer functions did not exceed 0.004 (Rundquist et al. 2004). The dual-fiber system methodology allowed data to be collected under variable illumination conditions (usually prohibitive for the single-instrument technique) without requiring absolute calibration of the radiometers (Dall'Olmo 2005).

The spectral data for Japan's Monobe River were collected using a single Analytical Spectral Devices SpecPro Full Range (FR) spectroradiometer. This portable spectrometer combines three spectrometers to cover the wavelength range from 350 to $2500 \mathrm{~nm}$. Reflectance was calculated as a simple ratio between upwelling radiance from the target and upwelling radiance from a reference panel:

$$
\% R(\lambda)=\left[L(\lambda)_{\mathrm{t}} / L(\lambda)_{\mathrm{cal}}\right] \times R(\lambda)_{\mathrm{cal}} \times 100
$$




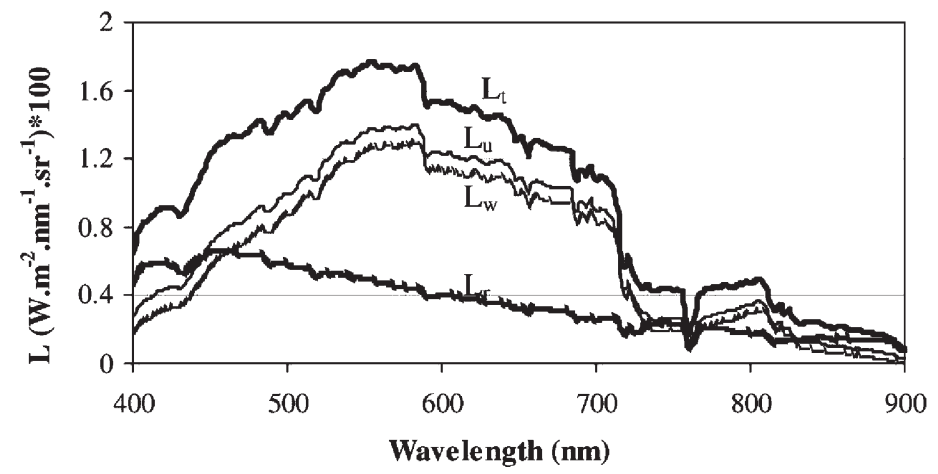

Figure 1. Comparison of the above water and subsurface upwelling radiance.

\section{Results and Discussion}

First, the above-water and below-water upwelling spectral radiances were compared. The upwelling above-water surface radiance $L_{w}(\lambda)$ was computed by Equation $(1) . L_{s}(\lambda)$ was measured by pointing the sensor in the direction of the solar zenith (detailed in Doxaran et al. 2002). In Equation (2), $L_{\mathrm{r}}(\lambda)$ was computed from $L_{\mathrm{s}}(\lambda)$ by assuming $\rho \approx 0.022$ (Austin 1974, Mobley 1999). The comparison between measured and computed spectral radiance is presented in Figure 1.

It is evident from Figure 1 that there is a notable contribution of surface-reflection to the total upwelling radiance. The difference between above-water surface total upwelling radiance $L_{t}(\lambda)$ and above-surface water-leaving radiance $L_{w}(\lambda)$ documents the fact that the contribution of surface-reflection effects was $70 \%$ at $400 \mathrm{~nm}, 40 \%$ at $500 \mathrm{~nm}, 25 \%$ from 600 to $700 \mathrm{~nm}$ and 40 to $70 \%$ from 800 to $900 \mathrm{~nm}$. A comparison of $L_{t}(\lambda)$ and $L_{u}(\lambda)$ indicates that the difference was more apparent in the visible range of the spectrum with the maximum difference at $480 \mathrm{~nm}$ and minimum at $655 \mathrm{~nm}$. The accurate retrieval of $L_{\mathrm{w}}(\lambda)$ from the measured above-water total upwelling signal is dependent on a proportionality factor $\rho(0.022$, in our case). Surface-reflection effects are pronounced and the success of this correction is associated with the appropriate value of $\rho$. The ratio between computed $L_{w}(\lambda)$ and measured $L_{\mathrm{u}}(\lambda)$ ranges between 0.6 and 0.9 . It shows that the approximated value of 0.54, as found in literature for the plane sea surface (Mobley 1999, Doxaran et al. 2004) is not expected to be valid in the case of inland waters. Moreover, the ratio is not constant and varies with the wavelength.

Next, the above-surface and below-surface measured reflectances were compared, and plotted for the Altamaha, St Mary's and Monobe Rivers in Figures 2a, 2b and 2c, respectively. For the purpose of comparing and evaluating spectral reflectances, the above-water upwelling radiances were not corrected for the surface-reflection effects in the calculation of above-water surface spectral reflectances. As expected, the above-water surface reflectances tended to be slightly higher than the subsurface reflectances. The maximum above-surface reflectances were about $6 \%$ in the visible spectrum for all the three rivers. The corresponding below-surface reflectance measurement was 1 to $2 \%$ lower, respectively, for the same sampling sites. SDs calculated for above-surface and below-surface spectral reflectances tended to be higher, for the former as compared with the latter. Minimal variation was noted in the red spectral region for all three rivers. 
a: Altamaha River

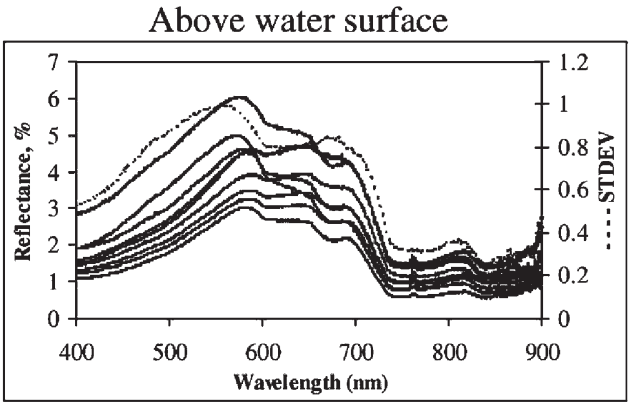

\section{Below water surface/Subsurface}

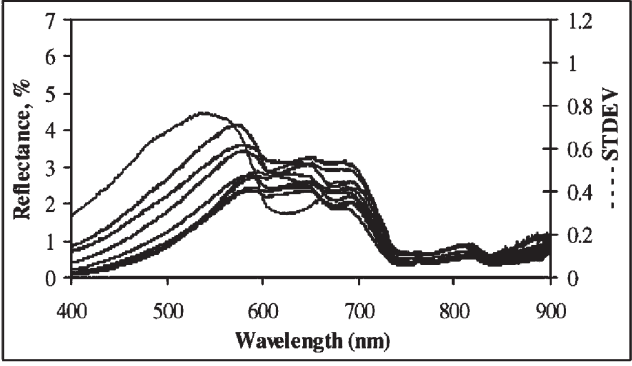

b: $\quad$ St. Marys River
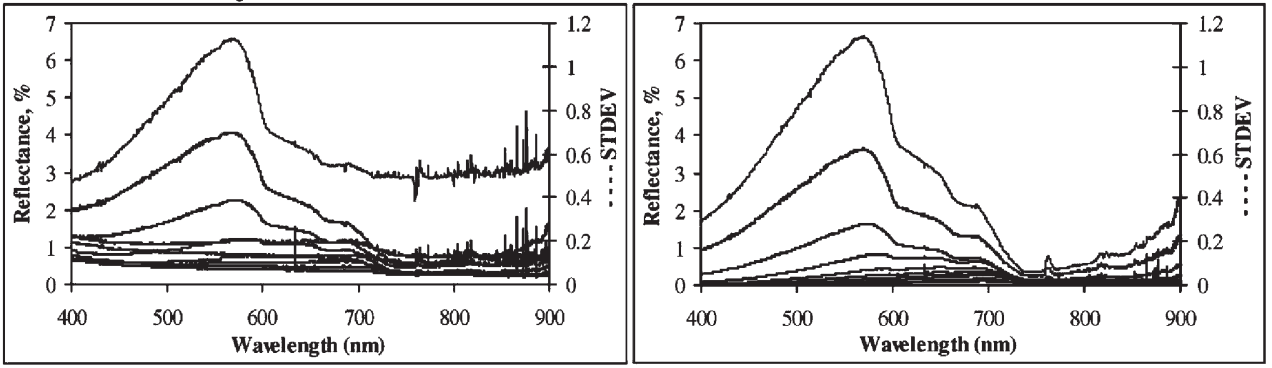

c: $\quad$ Monobe River
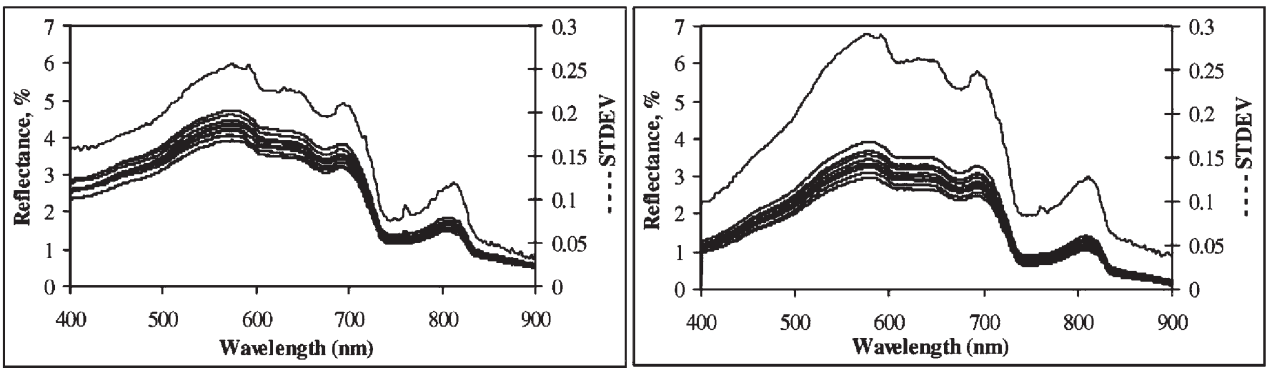

Figure 2. Comparison of above water surface and subsurface spectra.

To elucidate the comparison more thoroughly, the sampling points along the Altamaha river were selected and graphed as Figure 3. In that illustration, the maximum and minimum reflectance difference between the above-water and subsurface reflectance measurements are shown. At a wavelength of $577 \mathrm{~nm}$, a maximum of $6 \%$ and a minimum of $3.6 \%$ was observed for the above-surface reflectance in the case of the Altamaha river. The corresponding below-surface reflectances for the same sampling locations are 3 and $2.7 \%$, respectively. The spectral-reflectance difference of the sampling location with maximal reflectance is 3\%, and the difference for the sampling point with minimal reflectance is $0.9 \%$. The difference between above- and below-surface reflectances are not same for all the sampling stations. It varies significantly from point to point and for the same sampling point depending on wavelength.

With regard to the spectral component, the maximum difference was observed in the visible domain (400-550 $\mathrm{nm}$ ), and the difference tends to decrease towards longer visible wavelengths but increases slightly at near infrared (NIR) wavelengths. The difference 

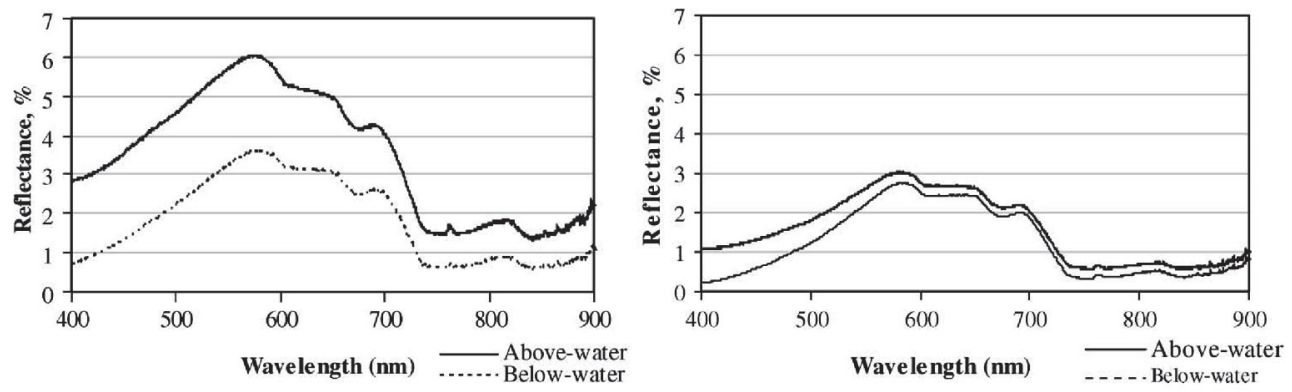

Figure 3. Comparison between the sampling points with maximum and minimum reflectance difference at Altamaha river.

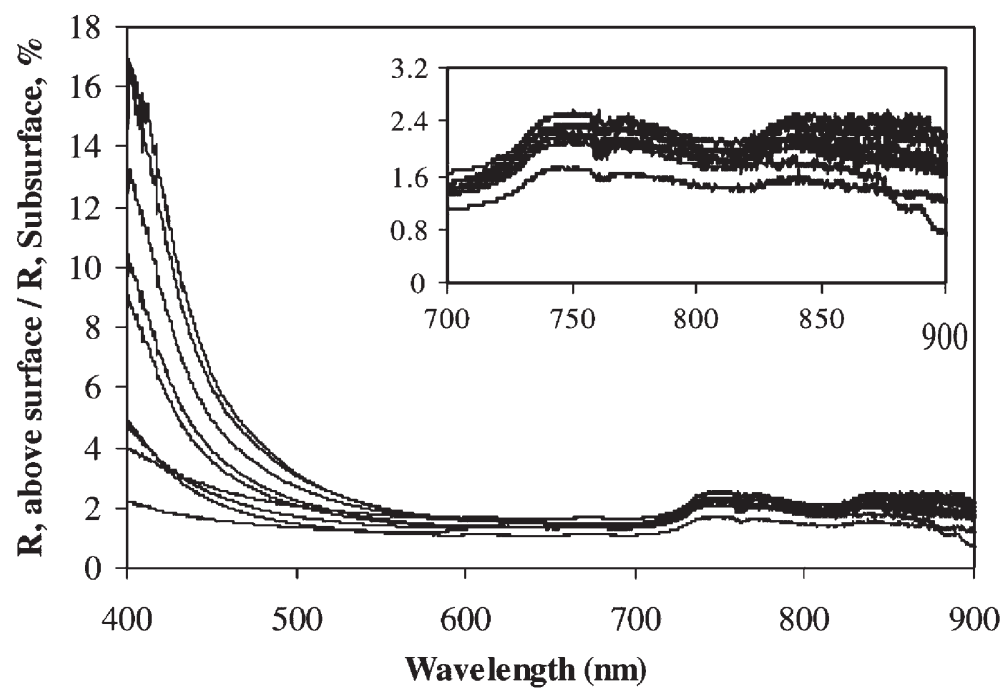

Figure 4. Correlation between the above and subsurface reflectance ratio versus wavelength at Altamaha river.

is almost constant in the blue and green domain; however, it was not consistent in the red region where the difference was minimal throughout. So, the difference generally decreased with increasing wavelength, and the effect of surface reflection was minimal near $750 \mathrm{~nm}$. We therefore conclude that surface-reflection effects changed the magnitude of the spectra; however, the shapes of the spectra were similar for all the cases. A similar kind of spectral behavior was noticed at all sampling points located in all the rivers. It leads to the conclusion that surface reflection only affects the magnitude of the reflectance and not the nature and shape of the spectral signatures.

The ratio between the above- and below-surface reflectances was also computed for the three rivers (Figure 4). It is interesting to note that the ratio differs for all sampling points at the same wavelength and for the same sampling point along both the visible- and nearinfrared regions. The maximum variation in the ratio was observed for the wavelength 400-500 nm (Figure 4). SDs of reflectance were calculated for all the above-water versus below-water reflectance datasets. For the Altamaha river, all the SDs of the above-water re- 
flectance measurements in the visible range were between 0.5 and $0.8 \%$, and 0.6 and $0.3 \%$ in the NIR. However, the SD of the below-surface reflectance measurements in the visible range were between 0.2 and $0.5 \%$, and 0.3 and $0.1 \%$ in the NIR. The SD of the above-water and subsurface reflectance ratios for all the sampling points were between 5 and $0.2 \%$ in the visible range, and were between, 0.2 and $0.4 \%$ in the NIR. A similar result was observed for the Monobe River. However, for the St Mary's River, the reflectance ratio is more than 100 at some sampling points in the visible region, and almost same trend exists for the NIR. We attribute the differences to the variations in the rivers themselves. The St. Mary's is very high in CDOM in its upstream segment. The spectral measurements of all the sampling points for a given river were taken under the same conditions and nearly simultaneously but, there is no symmetry in the above-water and below-water reflectance ratios. It means that the surface-reflection effects are prominent in all cases, but the contribution of that phenomenon is not same for even one water body. The above-water reflectance measurements were strongly influenced by surface conditions, again highlighting the fact that researchers should be aware of such problems during the collection of spectral data.

\section{Conclusions}

There are numerous components that together comprise the 'surface condition' of the water at any given location or sensor field of view. Water-quality components such as suspended inorganic material, colored dissolved organic or density of algal phytoplankton may influence the condition of surface waters within a given sensor field of view. But, our research indicates that despite variations in the mix of individual water-quality components, surface waves and resulting sun glint are important factors that seriously impact the collection of spectral data, especially when done by means of sensors positioned above the surface of the water body under study. In addition, the particular situation with each field of view on the surface of the water may be changing rapidly on windy days, so the problem is further exacerbated. On the positive side, however, we found that the effects associated with surface reflection only modify the magnitude of the upwelling signal, not the general shape of the spectral profile.

Our research underscores the need to conduct in situ measurement of surface waters using spectroradiometers equipped with fiber optics to allow subsurface sampling. The comparison between above-surface and below-surface reflectance measurement demonstrates, as noted above, that the condition of the surface has a noticeable effect on reflectance measured above the water. That surface condition is diminished or eliminated where spectral measurements are acquired slightly below the surface of the medium.

The retrieval of water-leaving signals by removing surface-reflection effects from the total upwelling-radiance signals by assuming a value $\rho$ is not effective. We find that such a procedure led to an unsatisfactory result and does not seem to provide a solution to the problem. The functional dependency of $\rho$ on various influencing parameters may lead to over- or under-estimation of $L_{w}(\lambda)$. We suggest that the perturbations in spectral measurements made above the surface of a water body are complex and presently there is no reliable method for their removal.

We also documented a spectral component to the variability in reflectance measured above the surface including a range of $25-70 \%$ in the visible spectrum and $40-70 \%$ in the 
NIR. The results of this portion of the investigation are not easily explained at present, and more research is certainly warranted. Moreover, the influence of surface-reflection effects on remote sensing imagery from an airborne or satellite-based platform remains to be found, and needs investigation.

Acknowledgements - The authors acknowledge the financial assistance provided by Kochi University of Technology (KUT), Japan and logistical support provided by the Center for Advanced Land Management Information Technologies (CALMIT), University of Nebraska-Lincoln.

\section{References}

Austin, R. W. (1974) Inherent spectral radiance signatures of the ocean surface. Ocean color analysis (Final Technical Report) p. 195. University of California, Scripps Institute of Oceanography, La Jolla, CA - 2.1-2.20

Dall'Olmo, G. (2005) Effect of bio-optical parameter variability on the remote estimation of chlorophyll-a concentration in turbid productive waters: experimental results. Applied Optics 44:3, pp. 412-422.

Doxaran, D., Cherukuru, R. C. and Lavender, S. (2004) Estimation of surface reflection effects on upwelling radiance field measurements in turbid waters. Journal of Optics A: Pure and Applied Optics 6, pp. 690-697.

Doxaran, D. et al. (2002) Spectral signature of highly turbid waters: application with SPOT data to quantify suspended particulate matter concentrations. Remote Sensing of Environment 81, pp. 149-161.

Environmental Protection Division (EPD) (2003) Altamaha River Basin Management Plan. Georgia Department of Natural Resources, Atlanta, GA; http:// www.gaepd.org/Documents/altamaha.html

Han, L. and Rundquist, D. (1998) The impact of a wind-roughened water surface on remote measurements of turbidity. International journal of remote sensing 19:1, pp. 195-201.

Hooker, S. (2002) An evaluation of above- and in-water methods for determining water-leaving radiances. Journal of Atmospheric and Oceanic Technology 19, pp. 486-515.

Hooker, S. and Maritorena, S. (2000) An evaluation of oceanographic radiometers and deployment methodologies. Journal of Atmospheric and Oceanic Technology 17, pp. 811-830.

Milton, E. (1987) Principles of field spectroscopy. International Journal of Remote Sensing 8:12, pp. 1807-1827.

Milton, E., Fox, P. and Michael, E. S. (2006) Progress in field spectroscopy. IEEE International Geoscience and Remote Sensing Symposium IGARSS 2006 pp. 1966-1968.

Mobley, C. (1989) A numerical model for computation of radiance distributions in natural waters with wind roughened surfaces. Limnology and Oceanography 34:8, pp. 1473-1283.

Mobley, C. (1999) Estimation of the remote-sensing reflectance from above-surface measurements. Applied Optics 38, pp. 7442-7455.

Morel, A. and Gentili, B. (1996) Diffuse reflectance of oceanic waters. III. Implication of bidirectionality for the remote-sensing problem. Applied Optics 35, pp. 4850-4861.

Rundquist, D. (2001) Field techniques in remote sensing: learning by doing. Geocarto International 16, pp. 83-88.

Rundquist, D. et al. (2004) Collecting spectral data over cropland vegetation using machine-positioning versus hand-held positioning of the sensor. Computers and Electronics in Agriculture 43, pp. 173-178. 